\title{
A Critical Role of Erythropoietin Receptor in Neurogenesis and Post-Stroke Recovery
}

\author{
Peter T. Tsai, ${ }^{1,4 *}$ John J. Ohab, ${ }^{2 *}$ Nathalie Kertesz, ${ }^{1}$ Matthias Groszer, ${ }^{1}$ Cheryl Matter, ${ }^{1,3}$ Jing Gao, ${ }^{1}$ Xin Liu,,${ }^{1,3,4}$ \\ Hong $\mathrm{Wu},{ }^{1,4}$ and $\mathrm{S}$. Thomas Carmichael ${ }^{2}$ \\ Departments of ${ }^{1}$ Molecular and Medical Pharmacology, ${ }^{2}$ Neurology, and ${ }^{3}$ Pathology and Laboratory Medicine, and ${ }^{4}$ Molecular Biology Institute, University \\ of California at Los Angeles, Los Angeles, California 90095
}

\begin{abstract}
Erythropoietin (EPO) is the principal growth factor regulating the production of red blood cells. Recent studies demonstrated that exogenous EPO acts as a neuroprotectant and regulates neurogenesis. Using a genetic approach, we evaluate the roles of endogenous EPO and its classical receptor (EPOR) in mammalian neurogenesis. We demonstrate severe and identical embryonic neurogenesis defects in animals null for either the Epo or EpoR gene, suggesting that the classical EPOR is essential for EPO action during embryonic neurogenesis. Furthermore, by generating conditional EPoR knock-down animals, we demonstrate that brain-specific deletion of EpoR leads to significantly reduced cell proliferation in the subventricular zone and impaired post-stroke neurogenesis. EpoR conditional knockdown leads to a specific deficit in post-stroke neurogenesis through impaired migration of neuroblasts to the peri-infarct cortex. Our results suggest that both EPO and EPOR are essential for early embryonic neural development and that the classical EPOR is important for adult neurogenesis and for migration of regenerating neurons during post-injury recovery.
\end{abstract}

Key words: erythropoietin; erythropoietin receptor; neurogenesis; ischemia; post-injury recovery; subventricular zone

\section{Introduction}

Erythropoietin (EPO) is a cytokine that plays critical roles in hematopoiesis. Both Epo and the classical EpoR are expressed in the nervous system during development and in adult (Digicaylioglu et al., 1995), and their expression levels are upregulated after hypoxic injury (Bernaudin et al., 1999). Pharmacological doses of EPO promote neural stem cell proliferation, survival, and differentiation in vitro (Studer et al., 2000; Shingo et al., 2001) and increased neuroblast migration to areas exposed to ischemic damage in vivo (Wang et al., 2004). Exogenous EPO is neuroprotective and neurotrophic in diverse CNS injury models, including hypoxic injury (Brines et al., 2000). Recently, an EPO derivative has also been identified to have a protective role in neuronal tissue and to signal by binding to a heteroreceptor, consisting of the classical erythropoietin receptor (EPOR) (Leist et al., 2004) and the common $\beta$ receptor $(\beta \mathrm{cR})$ for granulocyte macrophage colony-stimulating factor and interleukin- 3 and -5 receptors

Received June 23, 2005; revised Dec. 9, 2005; accepted Dec. 14, 2005.

This work was supported in part by the Larry L. Hillblom Foundation and the Nathan Shappell Fund (S.T.C.) and by the Brain Tumor Society Award and the James S. McDonnell Foundation Award (X.L. and H.W.). P.T.T. and C.M. were supported in part by the Medical Scientist Training Program training grant and the Engene V. Cota Robles Award by the Graduate Division through the University of California Office of the President. H.W. is a V Foundation scholar. J.0. was supported by the UCLA Training Program in Neural Repair. We thank Dr. Angus Sinclair (Amgen, Thousand Oaks, (A) and members of our laboratories for helpful comments on this manuscript.

*P.T.T. and J.J.O. contributed equally to this work.

Correspondence should be addressed to either of the following: Dr. Hong Wu, Department of Molecular and Medical Pharmacology, Geffen School of Medicine at University of California at Los Angeles, CHS 23-214, Los Angeles, CA 90095, E-mail: hwu@mednet.ucla.edu; or Dr. S. Thomas Carmichael, Department of Neurology, 635 Charles Young Drive South, University of California at Los Angeles, Los Angeles, CA 90095, E-mail: scarmichael@ mednet.ucla.edu.

DOI:10.1523/JNEUROSCI.4480-05.2006

Copyright $\odot 2006$ Society for Neuroscience $\quad 0270-6474 / 06 / 261269-06 \$ 15.00 / 0$
(Brines et al., 2004). However, the endogenous role of EPO and the role of the classical EPOR in neuroprotection and neurogenesis after stroke have not been defined. In this study, we evaluate the roles for endogenous EPO and the classical EPOR in nervous system development and repair using knockout of Epo and complete and conditional knockout of the EpoR.

\section{Materials and Methods}

Generation of hGFAP-Cre;EpoR floxp/floxp and hGFAP-Cre;EpoR floxp/mice. Generation of $E \mathrm{PO}^{-/-}$and $E \mathrm{P} o \mathrm{R}^{-/-}$mice have been described previously (Wu et al., 1995). Timing of embryos at early gestational stages was determined by counting somite numbers (Lee et al., 2001). Conditional knockout of EpoR receptor was done using the loxp/Cre system (supplemental material, available at www.jneurosci.org). The specificity of EpoR excision was evaluated by PCR (see Fig. 2), and EpoR knockdown was evaluated by RT-PCR using EpoR and Actin primers described previously (Digicaylioglu et al., 1995; Yamaji et al., 1996).

In situ hybridization. Nonradioactive whole-mount mRNA in situ hybridization for Epo and $E p o R$ was performed as described previously (Lee et al., 2001; Kertesz et al., 2004).

Stroke model. Stroke was produced in C57BL/6 mice and EpoR conditional knock-down ( $h G F A P-C r e ; E p o R^{\text {floxp floxp }}$ ) animals (Carmichael, 2005 ) with distal branch of the middle cerebral artery cauterization followed by 15 min bilateral common carotid occlusion.

Immunohistochemistry. Bromodeoxyuridine (BrdU; $50 \mathrm{mg} / \mathrm{kg}$, i.p., in $0.9 \%$ saline; Sigma, St. Louis, $\mathrm{MO}$ ) was given twice daily for $2 \mathrm{~d}$ before the animals were killed, or pulse-labeled with a single injection $(100 \mathrm{mg} / \mathrm{kg}$, i.p.). At 3, 5, and $7 \mathrm{~d}$ after stroke and in control animals ( $n=4-6$ for each group), tissue was processed for BrdU and doublecortin (DCX) immunostaining (supplemental material, available at www.jneurosci.org). Sections were analyzed with bright-field and epifluorescence microscopy (Leica DMLB) or with laser confocal microscopy (Leica TCS SP MP).

Stereology. Stereological quantification was performed on serial sec- 
tions through the anterior subventricular zone (SVZ), olfactory bulb, and peri-infarct cortex using unbiased counting with the optical fractionator technique (supplemental material, available at www.jneurosci.org).

Infarct volume. Infarct volume was measured $7 \mathrm{~d}$ after stroke in hGFAP-Cre;EpoR floxp $/-^{-}$and control mice ( $n=5$ and 4 , respectively) (Katsman et al., 2003; Li et al., 2005).

Statistics. Post-stroke SVZ counts were tested with factorial ANOVA and Bonferroni's post hoc testing (Statview 5.0.1; SAS Institute, Cary, $\mathrm{NC}$ ). Infarct volume, SVZ, and olfactory bulb counts were tested with two-sample $t$ testing assuming unequal variances (Excel; Microsoft, Redmond, WA).

\section{Results}

Sequential expression of EpoR and Epo in the developing brain and effects on embryonic development

To understand the function of EPO/EPOR in neurogenesis, Epo and EpoR expression was first determined with in situ hybridization. Whole-mount in situ hybridization of EpoR and Epo in embryonic day 7.5 (E7.5) to E11 embryos shows expression throughout the developing neural tube, with progressive expression in optic placode and forebrain and a delay of $0.5-1 \mathrm{~d}$ between EpoR and Epo expression in the same region (supplemental Fig. $1 a-f$, available at www.jneurosci. org as supplemental material). At E8.5, EpoR expression is confined to the neuroepithelium, a zone of precursors with high proliferation capacity (Fig. 1a, inset). Epo expression is absent at E8.5 (Fig. 1b) but appears by E9.0-E9.5 in the neuroepithelium (Fig. 1d). At E9.5-E10.5, EpoR expression rises in neural crest- and mesenchyme-derived cells (Fig. 1c,e, insets), followed by Epo expression in similar regions $1 \mathrm{~d}$ later (Fig. $1 f$ ). The temporal and spatial regulation of Epo and EpoR suggests a role for this ligand-receptor pair in early neurogenesis.

Both Epo and EpoR null embryos have incomplete neural tube closure at E10.5 (supplemental Fig. $1 h$, available at www.jneurosci. org as supplemental material), especially in the hindbrain. By E13.5, the neurogenesis defects become more evident, including wavy neural tubes (supplemental Fig. $1 j$, arrow, available at www.jneurosci.org as supplemental material), underdeveloped telencephalic regions (supplemental Fig. $1 j, l$, arrowhead, available at www.jneurosci.org as supplemental material). Although no major structures are absent in Epo and EpoR null mice, the mutant brains are consistently smaller and less developed than their littermate controls, particularly in the SVZ of the developing forebrain (Fig. 1h). In addition, the choroid plexus is severely underdeveloped in both null embryos, with a flattened cubiodal epithelium and underdeveloped capillary network (Fig, $1 i, l$ ). The identical phenotypes of Epo and EpoR null animals suggest that for early embryonic development, the classical EPOR is essential for EPO action.

\section{Generation of EpoR conditional knock-down mice}

EPO and EPOR modulate cardiogenesis, vasculogenesis, and neurogenesis (Wu et al., 1999; Studer et al., 2000; Shingo et al., 2001; Kertesz et al., 2004; Wang et al., 2004), raising the question of whether the classical EPOR exerts these functions in a cell autonomous manner. The erythrocyte deficiency in Epo and EpoR null animals results in systemic hypoxia (Wu et al., 1995), and the roles for EPO/EPOR in adult tissues cannot be evaluated in the null animals because of their early lethality (Wu et al., 1995). To define the role of EPOR in these nonhematopoietic tissues, we inserted loxp sites between the minimal promoter and exons 1-4 (supplemental Fig. 2, available at www.jneurosci.org as supplemental material). In contrast to the early lethal phenotype observed in EpoR null embryos, $E p o R^{\text {floxp floxp }}$ mice are viable and display no abnormal phenotypes compared with wild-type (WT) littermates in gross development, fertility, and physiology (data not shown), suggesting that introducing loxp sites into the endogenous EpoR locus does not disrupt its normal function.

\section{Brain-specific EpoR deletion}

$E p o R^{\text {floxp/floxp }}$ mice were crossed with hGFAP-Cre transgenic mice (Zhuo et al., 2001; Malatesta et al., 2003). The hGFAP promoter drives Cre expression in radial glial cells of the developing cortex, hindbrain, and cerebellum (Zhuo et al., 2001; Yue et al., 2005), resulting in efficient EpoR deletion in the brain and sparing of hematopoietic tissue (Fig. 2a,b, Mut). EpoR floxp/floxp $h$ GFAP-Cre ${ }^{+}$ mutants are viable and fertile, yielding Mendelian offspring distributions (data not shown), suggesting that neural-specific deletion of EpoR after E14 is not essential for embryonic or adult survival. Although expression is undetectable in the brain tissues, we cannot rule out the presence of remaining EpoR expression beyond our levels of detection, so these animals are described as EpoR conditional knock-down animals. Hematocrit, brain weight, and body weight of EpoR conditional knock-down mice are indistinguishable from their WT littermates (Fig. 2c). Normal brain architecture is preserved in $E p o R^{\text {floxpffloxp }} ; h G F A P-\mathrm{Cre}^{+}$animals in the cortex (Fig. $2 d$ ), olfactory bulbs, or cerebellum (data not shown). 


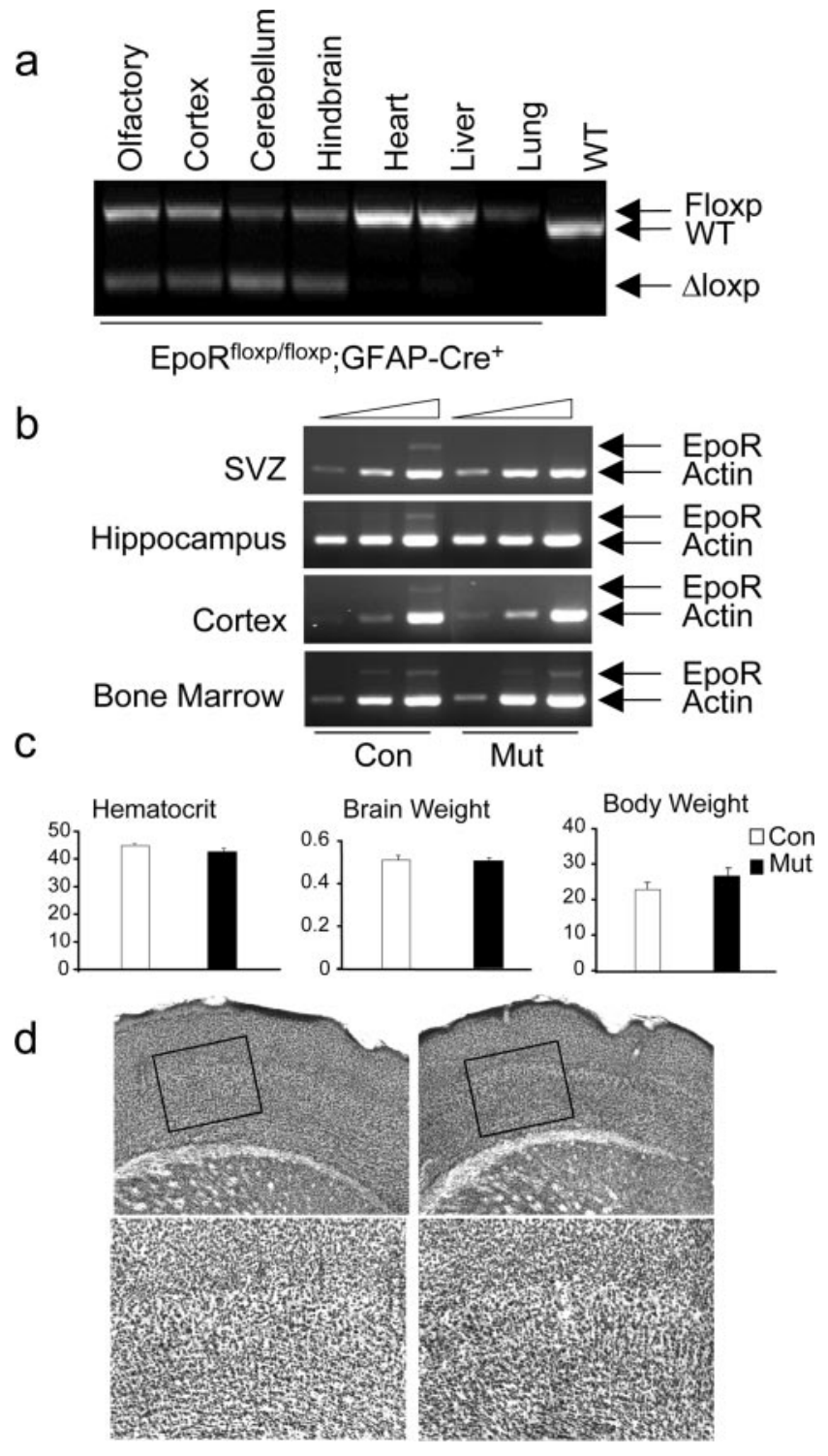

Figure 2. Analysis of EpoR conditional knock-down animals. a, PCR. Floxed, WT, and excised alleles ( $\Delta$ loxp) are indicated. $\boldsymbol{b}$, RT-PCR analysis for EpoR expression levels. $\boldsymbol{c}$, Hematocrit, brain weight, and body weight are unchanged in the mutants. Error bars indicate SDs. $\boldsymbol{d}$, Cresyl violet sections from control (left) and mutant (right) animals. The bottom panels show highermagnification views of the boxed areas. Con, Control; Mut, mutant.

\section{Neural-specific EpoR knockdown leads to reduced cell proliferation in the SVZ}

Exogenous EPO promotes proliferation, survival, and neuronal differentiation of neural stem cells in vitro (Ling et al., 1998; Studer et al., 2000; Shingo et al., 2001; Yu et al., 2002). To examine neurogenesis in vivo, we compared the SVZ of EpoR mutant mice with littermate controls. The mutant SVZ is decreased in volume (Fig. 3i) and has fewer cells compared with controls (Con, $18,573 \pm 1523 ;$ Mut, 14,661 $\pm 2131 ; p<0.03)$. After BrdU pulse, the mutant SVZ contains a significantly reduced number of $\mathrm{BrdU}^{+}$cells at postnatal day 15 , which is further reduced at 6 months (Fig. 3h). Despite reduced BrdU labeling in the SVZ, there is no difference in $\mathrm{BrdU}^{+}$olfactory bulb cells between the two conditions (Con, $8431 \pm 1820$ cells; Mut, $9068 \pm 1446$ cells; $p=0.16)$. These results provide the first evidence that EPOR plays essential roles in adult neurogenesis in vivo and suggests that $\mathrm{EPO} / \mathrm{EPOR}$ may regulate neural stem and progenitor cell proliferation, but not the normal pattern of neuroblast migration to the olfactory bulb.

\section{EPOR is not essential for protecting neurons from ischemic injury}

Previous studies that determined a neuroprotective effect of exogenous EPO (Sakanaka et al., 1998; Bernaudin et al., 1999; Siren et al., 2001) either evaluated stroke size $24 \mathrm{~h}$ after stroke, when the area of infarction is not yet complete in most rodent stroke models (Lipton, 1999), or used permanent focal ischemia, which produces a different pattern of neuronal injury and death compared with stroke models that involve reperfusion (Lipton, 1999; Carmichael, 2005). We used a focal stroke model with the infarct and reperfusion injury restricted to the sensorimotor cortex (Katsman et al., 2003; Carmichael et al., 2004). In this model, there is no statistically significant difference in infarct size between mutant (Fig. 4a) and controls (Fig. $4 b$ ) at day 3 (data not shown) and day 7 (Fig. $4 c$ ) after stroke ( $p=0.31$ ). This result suggests that, although higher doses of exogenous EPO may promote neuroprotection, endogenous levels of EPO and EPOR have limited roles in protecting neurons from ischemic reperfusion injury.

\section{EPOR is important for post-stroke neurogenesis}

Stroke induces migration of newly born neuroblasts from the SVZ into the area of injury in the first 7-14 d after the insult (Arvidsson et al., 2002; Parent et al., 2002; Jin et al., 2003), detected by the combination of pulse labeling with BrdU and staining for DCX, a microtubule-associated protein present in immature and migrating neurons (Feng and Walsh, 2001). As reported previously (Yang et al., 2004), there are no $\mathrm{DCX}^{+}$cells in the cortex of either control or mutant mice before stroke (Fig. 4h). After stroke, $\mathrm{DCX}^{+}$cells are found in subcortical white matter at day 3 (supplemental Fig. 3, available at www.jneurosci.org as supplemental material) and in the peri-infarct cortex at days 5 and 7, resulting in $>4000 \mathrm{DCX}^{+}$cells per animal in the periinfarct cortex (Fig. 4h). In both control and mutant animals, $\mathrm{DCX}^{+}$cells are labeled with BrdU given after the stroke (supplemental Fig. 4, available at www.jneurosci.org as supplemental material), and these cells are also immunoreactive for other markers of immature neurons or neural progenitor cells, such as PSA-NCAM and musashi (Gleeson et al., 1999; Okano et al., 2005) (supplemental Fig. 5, available at www.jneurosci.org as supplemental material). The number of $\mathrm{DCX}^{+}$cells between mutant and control animals remains the same on days 3 and 5 after stroke. However, EpoR conditional knock-down mice (Fig. $4 e, g$ ) show a 2.6 -fold reduction in the number of $\mathrm{DCX}^{+}$neuroblasts present in the cortex at day 7 compared with controls (Fig. $4 d, f)$.

The reduction of $\mathrm{DCX}^{+}$neuroblasts in the cortex of poststroke EpoR conditional knock-down mice may be attributable to reduced SVZ proliferation, reduced migration to the peri-infarct cortex, or increased cell death in the peri-infarct cortex. To examine proliferation, the number of $\mathrm{BrdU}^{+}$cells in the SVZ was quantified after stroke (Fig. $3 h$ ). Control mice show a significant decrease in $\mathrm{BrdU}$ incorporation at day $3\left(F_{(5,21)}=8.072 ; p=\right.$ 0.002 ) (supplemental Fig. $5 d, h$, available at www.jneurosci.org as supplemental material), during the period in which $\mathrm{DCX}^{+}$cells migrate from the SVZ toward the peri-infarct cortex and then a return to baseline at day 7 (Fig. $3 f, h$ ). In contrast, the mutant mice have a reduced number of $\mathrm{BrdU}^{+}$cells and display no change at any time point after stroke (Fig. $3 c, e, g, h$ ). The SVZ volume shows similar differences between control and mutant before and after stroke (Fig. 3i). Thus, the mutant SVZ not only 
has reduced BrdU labeling at baseline but also lacks any significant response to stroke. To determine cell migration and death after stroke, a cohort of DCX cells was labeled by administering BrdU on days 3-5 after stroke and tracking these cells in the peri-infarct cortex on days 5 and 7 . In controls, $49 \pm 7 \%$ of $\mathrm{DCX}^{+}$cells are $\mathrm{BrdU}^{+}$at day 5 with further increases to $68 \pm 6 \%$ by day 7 , indicating a continued migration of this cohort of $\mathrm{DCX}^{+}$ cells into the peri-infarct cortex by day 7 . In mutants, the percentage of $\mathrm{DCX}^{+} /$ $\mathrm{BrdU}^{+}$cells on day 5 is similar to controls ( $p=0.35$ ) but fails to increase by day 7 $(55 \pm 9 \% ; p=0.53$, MUT day 3 vs day 7$)$. This indicates that there is a failure of continued neuroblast migration into the periinfarct cortex in EpoR conditional knockdown. To determine whether there is an increase in cell death with EpoR conditional knockdown, the number of terminal deoxynucleotidyl transferasemediated biotinylated UTP nick end labeling (TUNEL)-positive cells was quantified in the peri-infarct cortex on days 5 and 7 after stroke. There is no significant difference in the number of TUNEL cells in the per-infarct cortex at these two time points ( $5 \mathrm{~d}$ Con, $45 \pm 19.6$; 5 d Mut, $43.5 \pm 11.5$; 7 d Con, $42.8 \pm 13.3$; $7 \mathrm{~d}$ Mut, $37.8 \pm 14.2 ; p>0.63$ for all comparisons). Coupled with the significant loss of $\mathrm{DCX}^{+}$cells in the mutant periinfarct cortex from days 5-7 (Fig. 4h), these data show that neuroblasts migrate to the peri-infarct cortex in which a subset then undergo cell death. Continued migration of neuroblasts occurs in control animals such that the overall number is maintained, but there is no continued migration in mutant, and the overall number of neuroblasts declines over time.

\section{Discussion}

In this study, we provide the first genetic demonstration that EPO and EPOR play essential roles in regulating embryonic and adult neuronal development and function. We demonstrate Epo and EpoR expression during critical periods of neuronal development as well as significantly aberrant neurogenesis in null animals. Then, using a model whereby neuronal EpoR expression is specifically reduced in the brain, we demonstrate a critical role for EPOR in adult neurogenesis and in the migration of newly born neuroblasts to areas of injury. Finally, EpoR conditional knock-down mice display no significant differences in infarct size versus control mice when exposed to stroke, suggesting alternative mechanisms underlying the neuroprotective functions of EPO. bars indicate SDs. a

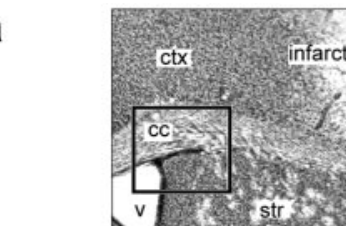

h
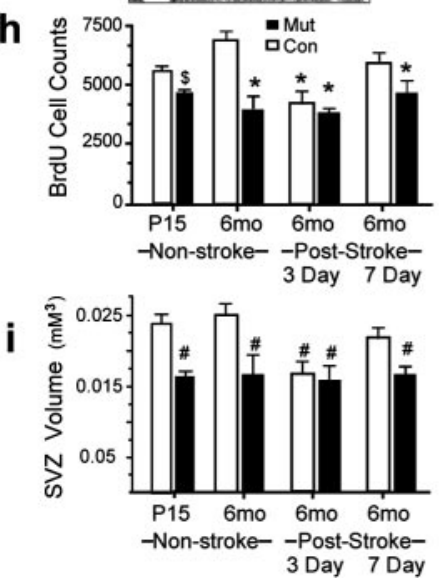
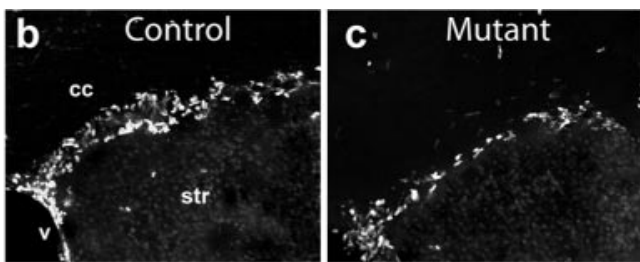

은
등
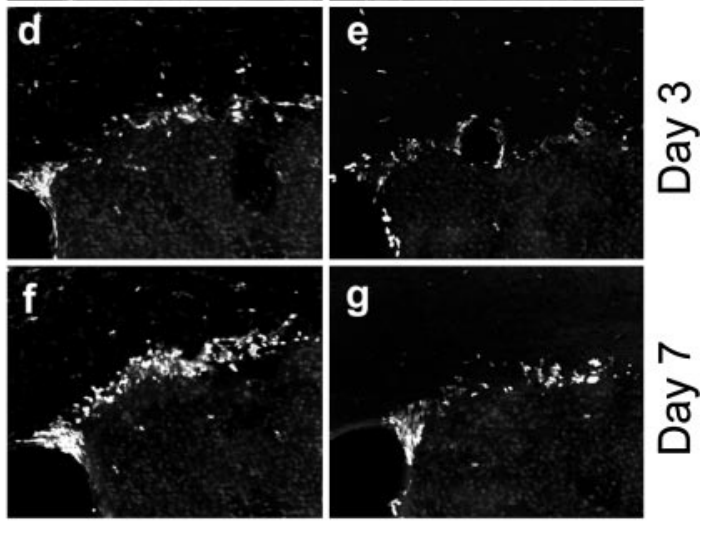

Figure 3. Quantification of BrdU labeling in the SVZ. $\boldsymbol{a}$, Cresyl violet section. The rectangle shows the location of $\boldsymbol{b}-\boldsymbol{g} . \boldsymbol{b}-\boldsymbol{g}$, BrdU-labeled cells in control $(\boldsymbol{b}, \boldsymbol{d}, \boldsymbol{f})$ and EpoR conditional knock-down $(\boldsymbol{c}, \boldsymbol{e}, \boldsymbol{g})$ animals in non-stroke $(\boldsymbol{b}, \boldsymbol{c}), 3 \mathrm{~d}$ after stroke $(\boldsymbol{d}, \boldsymbol{e})$, and $7 \mathrm{~d}$ after stroke $(\boldsymbol{f}, \boldsymbol{g})$ are shown. Scale bar, $50 \mu \mathrm{m} . \boldsymbol{h}, \boldsymbol{i}$, The graphs show quantifications of BrdU-labeled cells $(\boldsymbol{h})$ and SVZ volume before and after stroke (i). ${ }^{*} p \leq 0.004 ;{ }^{\#} p \leq 0.008 ;{ }^{\$} p=0.016$. Error bars indicate SDs. ctx, Cortex; str, stiatum; V, ventricle; cc, corpus callosum; P15, postnatal day 15; mo, month; Con, control; Mut, mutant. a

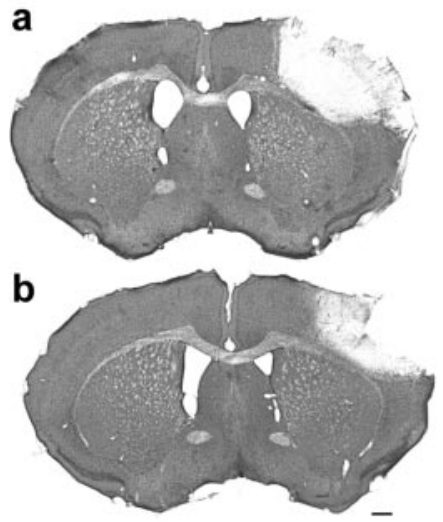

C

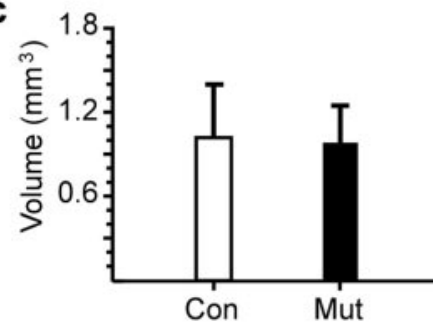

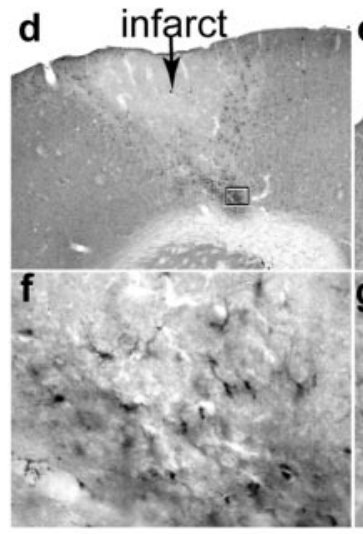

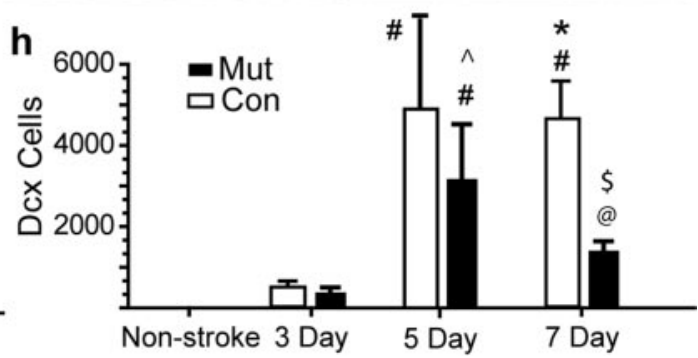

Figure 4. EpoR conditional knock-down leads to reduced neuroblast migration. $\boldsymbol{a}, \boldsymbol{b}$, Cresyl violet sections through the frontal cortex of mutant $(\boldsymbol{a})$ and control $(\boldsymbol{b}) 7 \mathrm{~d}$ after stroke. Scale bar, $500 \mu \mathrm{m}$. $\boldsymbol{c}$, Infarct volume $7 \mathrm{~d}$ after stroke was quantified. $\boldsymbol{d}-\boldsymbol{g}$, $\mathrm{DCX}{ }^{+}$cells in control $(\boldsymbol{d}, \boldsymbol{f})$ and mutant $(\boldsymbol{e}, \boldsymbol{g})$. The region within the box in $\boldsymbol{d}$ and $\boldsymbol{e}$ is enlarged in $\boldsymbol{f}$ and $\boldsymbol{g}$. Scale bars: $\boldsymbol{d}, 100 \mu \mathrm{m}$; $\boldsymbol{f}, 25 \mu \mathrm{m}$. $\boldsymbol{h}$, Stereological quantification of $D C X^{+}$cells. ${ }^{\#} p \leq 0.001$ versus all other conditions; ${ }^{*} p=0.008$ versus Mut at non-stroke stage; $p=0.02$ versus Mut at $7 \mathrm{~d}$; ${ }^{@} p<0.02$ versus $3 \mathrm{~d}$ Mut/Con and non-stroke; ${ }^{\$} p=0.002$ versus $7 \mathrm{~d}$ control. Error

EPO/EPOR are required for developmental neurogenesis

The role of EPO in the nervous system extends beyond tissue oxygenation. Epo and EpoR are expressed during critical periods of neuronal development, and Epo and EpoR null animals reveal 
defects in neurogenesis (Yu et al., 2002; present study). Here, we demonstrate that these defects are mediated through EPO binding to the classical EPOR. Neuronal defects in Epo null animals are identical to those seen in EpoR null animals, showing that EPO is acting through the EPOR during neuronal development. Recent studies have suggested an alternative receptor for EPO neuronal effects (Leist et al., 2004) and that $\beta c \mathrm{R}$ is essential for EPO neuroprotective actions (Brines et al., 2004). The identical hematopoietic and neuronal developmental phenotypes between Epo and EpoR null animals suggest that, for early embryonic development, the classical EPOR is essential for EPO action. Because $\beta \mathrm{cR}$ null animals are viable without hematopoietic, cardiac, or neuronal defects, EPO likely acts exclusively through EPOR homodimers for its roles in these tissues during development (Reed et al., 2000; Brines et al., 2004).

\section{EPOR is critical for adult and post-stroke neurogenesis}

Exogenous EPO can promote neurogenesis in vitro (Ling et al., 1998; Studer et al., 2000; Shingo et al., 2001). Our study, however, provides the first evidence that EPOR plays essential roles in adult neurogenesis in vivo. EpoR conditional knock-down animals have significantly reduced levels of BrdU incorporation in the SVZ and diminished SVZ cell number and volume, suggesting that EPOR plays a critical function in maintaining dividing cell numbers in the adult SVZ.

Studies in large stroke models in the rat report increased labeling of proliferating cells in the SVZ and migration of newly born neuroblasts from the SVZ to peri-infarct tissue (Arvidsson et al., 2002; Parent et al., 2002; Jin et al., 2003). In the present study, focal stroke is restricted to the mouse somatosensory cortex, with $>1 \mathrm{~mm}$ distance to the SVZ. There is a biphasic proliferative response in the $\mathrm{SVZ}$ in this model and a robust migration of neuroblasts to the peri-infarct cortex. Our study demonstrates that EPOR also plays an essential role in this neurogenic response to ischemia. EpoR conditional knock-down animals do not display this biphasic SVZ response but instead maintain the reduced control levels of BrdU labeling after stroke. Despite this lack of SVZ response, these animals appear to possess a normal initial post-stroke neuroblast migration to the peri-infarct cortex. After this initial migration, significant numbers of neuroblasts are lost in the peri-infarct cortex in the EpoR knock-down animals (Fig. $4 h$ ), and there is no continued migration of neuroblasts to replace them.

\footnotetext{
Alternative mechanisms for EPO-mediated neuroprotection Exogenous EPO has been shown to play a neuroprotective role during the ischemic response of the brain by preventing neuronal apoptosis (Sakanaka et al., 1998; Bernaudin et al., 1999; Siren et al., 2001). However, our data show no difference in infarct volume after conditional deletion of EpoR. This result suggests that although higher doses of exogenous EPO promotes neuroprotection, there is a limited role of the endogenous EPO system in neuroprotection. Alternatively, the neuroprotective actions of EPO may also be mediated via routes other than binding the classical EPOR on neurons, such as through blood vessels. Exogenous EPO has been demonstrated to increase cerebral vasculature at infarct sites (Marti et al., 2000; Wang et al., 2004), with subsequent increased oxygen delivery perhaps resulting in neuroprotection. EPO may also act as a neuroprotectant by binding a receptor that contains $\beta \mathrm{cR}$ but lacks the classical EPOR (Brines et al., 2004). Thus, upregulation of other receptor complexes may compensate for loss of the classical EPOR and mediate the neu-
}

roprotective effects of EPO in the conditional knock-down animals.

\section{References}

Arvidsson A, Collin T, Kirik D, Kokaia Z, Lindvall O (2002) Neuronal replacement from endogenous precursors in the adult brain after stroke. Nat Med 8:963-970.

Bernaudin M, Marti HH, Roussel S, Divoux D, Nouvelot A, MacKenzie ET, Petit E (1999) A potential role for erythropoietin in focal permanent cerebral ischemia in mice. J Cereb Blood Flow Metab 19:643-651.

Brines M, Grasso G, Fiordaliso F, Sfacteria A, Ghezzi P, Fratelli M, Latini R, Xie QW, Smart J, Su-Rick CJ, Pobre E, Diaz D, Gomez D, Hand C, Coleman T, Cerami A (2004) Erythropoietin mediates tissue protection through an erythropoietin and common beta-subunit heteroreceptor. Proc Natl Acad Sci USA 101:14907-14912.

Brines ML, Ghezzi P, Keenan S, Agnello D, de Lanerolle NC, Cerami C, Itri LM, Cerami A (2000) Erythropoietin crosses the blood-brain barrier to protect against experimental brain injury. Proc Natl Acad Sci USA 97:10526-10531.

Carmichael ST (2005) Rodent stroke models: size, mechanism and purpose. NeuroRx 2:396-409.

Carmichael ST, Tatsukawa K, Katsman D, Tsuyuguchi N, Kornblum HI (2004) Evolution of diaschisis in a focal stroke model. Stroke 35:758-763.

Digicaylioglu M, Bichet S, Marti HH, Wenger RH, Rivas LA, Bauer C, Gassmann M (1995) Localization of specific erythropoietin binding sites in defined areas of the mouse brain. Proc Natl Acad Sci USA 92:3717-3720.

Feng Y, Walsh CA (2001) Protein-protein interactions, cytoskeletal regulation and neuronal migration. Nat Rev Neurosci 2:408-416.

Gleeson JG, Lin PT, Flanagan LA, Walsh CA (1999) Doublecortin is a microtubule-associated protein and is expressed widely by migrating neurons. Neuron 23:257-271.

Jin G, Omori N, Li F, Nagano I, Manabe Y, Shoji M, Abe K (2003) Protection against ischemic brain damage by GDNF affecting cell survival and death signals. Neurol Res 25:249-253.

Katsman D, Zheng J, Spinelli K, Carmichael ST (2003) Tissue microenvironments within functional cortical subdivisions adjacent to focal stroke. J Cereb Blood Flow Metab 23:997-1009.

Kertesz N, Wu J, Chen TH, Sucov HM, Wu H (2004) The role of erythropoietin in regulating angiogenesis. Dev Biol 276:101-110.

Lee R, Kertesz N, Joseph SB, Jegalian A, Wu H (2001) Erythropoietin (Epo) and EpoR expression and 2 waves of erythropoiesis. Blood 98:1408-1415.

Leist M, Ghezzi P, Grasso G, Bianchi R, Villa P, Fratelli M, Savino C, Bianchi M, Nielsen J, Gerwien J, Kallunki P, Larsen AK, Helboe L, Christensen S, Pedersen LO, Nielsen M, Torup L, Sager T, Sfacteria A, Erbayraktar S, et al. (2004) Derivatives of erythropoietin that are tissue protective but not erythropoietic. Science 305:239-242.

Li S, Zheng J, Carmichel ST (2005) Differences in ischemic injury after stroke between agend and young adults. Neurobiol Dis 18:432-440.

Ling ZD, Potter ED, Lipton JW, Carvey PM (1998) Differentiation of mesencephalic progenitor cells into dopaminergic neurons by cytokines. Exp Neurol 149:411-423.

Lipton P (1999) Ischemic cell death in brain neurons. Physiol Rev 79:1431-1568.

Malatesta P, Hack MA, Hartfuss E, Kettenmann H, Klinkert W, Kirchhoff F, Gotz M (2003) Neuronal or glial progeny: regional differences in radial glia fate. Neuron 37:751-764.

Marti HH, Bernaudin M, Petit E, Bauer C (2000) Neuroprotection and angiogenesis: dual role of erythropoietin in brain ischemia. News Physiol Sci 15:225-229.

Okano H, Kawahara H, Toriya M, Nakao K, Shibata S, Imai T (2005) Function of RNA-binding protein Musashi-1 in stem cells. Exp Cell Res 306:349-356.

Parent JM, Vexler ZS, Gong C, Derugin N, Ferriero DM (2002) Rat forebrain neurogenesis and striatal neuron replacement after focal stroke. Ann Neurol 52:802-813.

Reed JA, Ikegami M, Robb L, Begley CG, Ross G, Whitsett JA (2000) Distinct changes in pulmonary surfactant homeostasis in common betachain- and GM-CSF-deficient mice. Am J Physiol Lung Cell Mol Physiol 278:L1164-L1171. 
Sakanaka M, Wen TC, Matsuda S, Masuda S, Morishita E, Nagao M, Sasaki R (1998) In vivo evidence that erythropoietin protects neurons from ischemic damage. Proc Natl Acad Sci USA 95:4635-4640.

Shingo T, Sorokan ST, Shimazaki T, Weiss S (2001) Erythropoietin regulates the in vitro and in vivo production of neuronal progenitors by mammalian forebrain neural stem cells. J Neurosci 21:9733-9743.

Siren AL, Fratelli M, Brines M, Goemans C, Casagrande S, Lewczuk P, Keenan S, Gleiter C, Pasquali C, Capobianco A, Mennini T, Heumann R, Cerami A, Ehrenreich H, Ghezzi P (2001) Erythropoietin prevents neuronal apoptosis after cerebral ischemia and metabolic stress. Proc Natl Acad Sci USA 98:4044-4049.

Studer L, Csete M, Lee SH, Kabbani N, Walikonis J, Wold B, McKay R (2000) Enhanced proliferation, survival, and dopaminergic differentiation of CNS precursors in lowered oxygen. J Neurosci 20:7377-7383.

Wang L, Zhang Z, Wang Y, Zhang R, Chopp M (2004) Treatment of stroke with erythropoietin enhances neurogenesis and angiogenesis and improves neurological function in rats. Stroke 35:1732-1737.

Wu H, Liu X, Jaenisch R, Lodish HF (1995) Generation of committed ery- throid BFU-E and CFU-E progenitors does not require erythropoietin or the erythropoietin receptor. Cell 83:59-67.

Wu H, Lee SH, Gao J, Liu X, Iruela-Arispe ML (1999) Inactivation of erythropoietin leads to defects in cardiac morphogenesis. Development 126:3597-3605.

Yamaji R, Okada T, Moriya M, Naito M, Tsuruo T, Miyatake K, Nakano Y (1996) Brain capillary endothelial cells express two forms of erythropoietin receptor mRNA. Eur J Biochem 239:494-500.

Yu X, Shacka JJ, Eells JB, Suarez-Quian C, Przygodzki RM, Beleslin-Cokic B, Lin CS, Nikodem VM, Hempstead B, Flanders KC, Costantini F, Noguchi CT (2002) Erythropoietin receptor signaling is required for normal brain development. Development 129:505-516.

Yue Q, Groszer M, Gil JS, Berk AJ, Messing A, Wu H, Liu X (2005) PTEN deletion in Bergmann glia leads to premature differentiation and affects laminar organization. Development 132:3281-3291.

Zhuo L, Theis M, Alvarez-Maya I, Brenner M, Willecke K, Messing A (2001) hGFAP-cre transgenic mice for manipulation of glial and neuronal function in vivo. Genesis 31:85-94. 